\title{
INCIDENCE OF MALFORMATION SYNDROMES AND CHROMOSOMAL ABNORMALITIES IN 22,063 NEWBORN INFANTS IN TOKYO
}

\author{
Makoto Higurashi, ${ }^{1}$ Sumio Imima, ${ }^{1}$ Tatsuya Takeshita, ${ }^{1}$ \\ Masaaki OdA, ${ }^{1}$ Kumiko TAKADAYA, ${ }^{2}$ and \\ Nobuo WATANABE ${ }^{3}$ \\ ${ }^{1}$ Department of Health Sciences, Yamanashi Medical College, Tamaho, \\ Nakakoma, Yamanashi 409-98, Japan \\ ${ }^{2}$ Department of Maternal and Child Health, University of Tokyo, \\ Bunkyo-ku, Tokyo 113, Japan \\ ${ }^{3}$ Department of Pediatrics, Kyorin University, Shinkawa, \\ Mitaka, Tokyo 181, Japan
}

\begin{abstract}
Summary A survey of the birth prevalence of congenital malformation syndromes and chromosomal abnormalities among newborn infants in Tokyo is reported. Of 22,063 consecutive newborn infants (11,348 male, 10,715 female), 51 had multiple congenital malformation syndromes. These included 3 with trisomy 13, 4 with trisomy 18, 24 with Down syndrome, 2 with cri-du-chat syndrome, 1 with 5 p partial trisomy, 1 with $10 p$ partial monosony, 1 with $4 \mathrm{p}$ partial monosomy, 1 with Hallermann-Streiff syndrome, 1 with Treacher-Collins syndrome, 2 with achondroplasia, 2 with arthrogryposis, 2 with hemihypertrophy, 1 with Wiedemann-Beckwith syndrome, 1 with asplenia, 1 with Klippel-Trenaunay-Weber syndrome, 1 with Marfan syndrome, 1 with Carpenter syndrome, 1 with Goldenhar syndrome, and 1 with aberrant tissue syndrome.

Of 6,977 phenotypically normal male babies, 6 were XYY individuals and 2 had Klinefelter syndrome; of 2,633 phenotypically female babies, one had Turner syndrome and one was triple X.
\end{abstract}

\section{INTRODUCTION}

In order to ascertain the frequency of specific malformation syndromes among newborn infants in Japan, a survey to determine the birth prevalence of congenital malformations and chromosomal abnormalities among newborn infants in Japan is in progress.

The present report describes the birth prevalence of specific malformation 
syndromes which has been evaluated in 22,063 consecutive live births in one large maternity hospital in Tokyo during a 10 -year period. Combined and multiple malformations that have not been established as specific entities are excluded from this report. The purpose of this paper is to report the following: the prevalence of several malformation syndromes among the general newborn population in Japan; the relationship between maternal ages and each malformation syndrome; a comparison of the birth weight of the affected infants with the intrauterine growth of normal Japanese babies.

\section{MATERIALS AND METHODS}

In this study we included 22,063 consecutive live-born infants delivered at one big Maternity Hospital in Tokyo between July 1, 1972 and December 31, 1982. This hospital, of which characteristics is the primary care is the largest maternity hospital in Hachiouji, a western suburb of Tokyo, and admits patients from all socioeconomic classes. The average birth rate was 2,101 per year during the period of this study. The distribution of the maternal ages at deliveries in this hospital is similar to that of the general population in Japan. Of the 22,063 babies examined, 11,348 were male and 10,715 female. Every newborn infant was examined within $24 \mathrm{hr}$ after delivery and malformations were recorded. Babies thought to have congenital malformations were noted and then reexamined by two pediatricians. Dermatoglyphic patterns and chromosomes were analyzed on these infants before discharge or death. Abnormal dermatoglyphic patterns have been studied in the Japanese (Higurashi et al., 1977; Matsui et al., 1969).

In our clinic, malformations associated with mental retardation and abnormal dermatoglyphic patterns have been shown to be highly suggestive of autosomal aberrations (Higurashi et al., 1980). Therefore, infants with malformations and abnormal dermatoglyphic were examined for chromosomal abnormality by karyotyping, although mental retardation could not be established until at least 4 months of age. The screening methods for chromosomal abnormality are shown in Fig. 1. Buccal mucosa cells were collected within 3 days after birth, coated on glass slides, and fixed overnight in methanol. The slides for the $\mathrm{X}$ chromatin test were stained by carbol fuchsin. The slides for $\mathrm{Y}$ chromatin test were stained by quinacrine mustard as the primary screening method. Besides this, when cases with abnormal $\mathrm{X}$ and $\mathrm{Y}$ chromosomes were suspected, secondary screening methods of peripheral blood samples for $\mathrm{Y}$ chromatin and of repeated buccal smears for $\mathrm{X}$ chromatin after 2 or 3 months of age were utilized in order to avoid false positive or negative results.

A monthly follow-up of each baby was conducted from birth to 12 months of age, under the Child Health Survey Programme of this hospital. Almost all infants except babies died whithin one month of age certainly had physical examinations at one month of age. As a result, some infants with congenital anomalies, who 


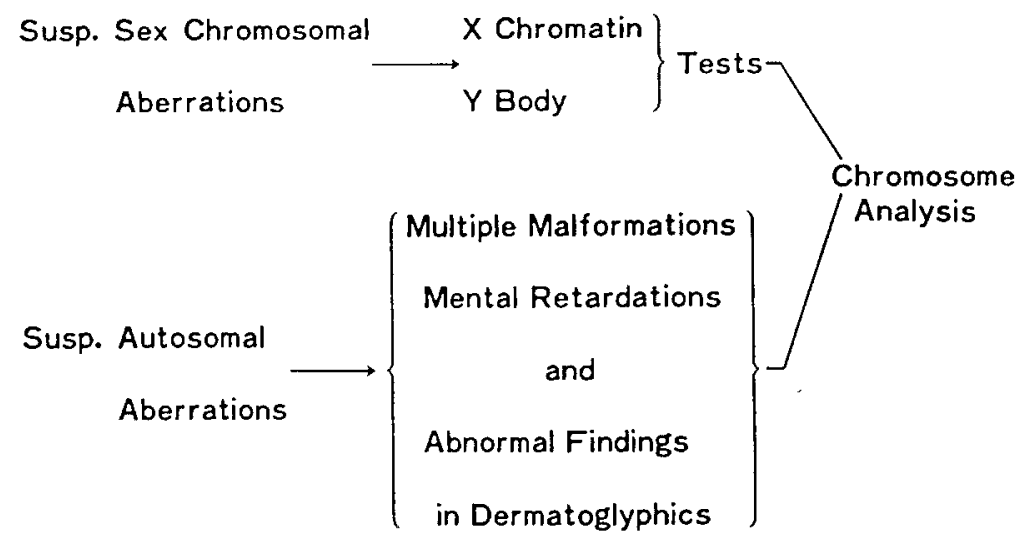

Fig. 1. Screening methods of chromosomal aberrations.

were not diagnosed at the initial clinical examination or on discharge, were diagnosed one month after birth during routine examinations by pediatricians.

Chromosome analysis was carried out on lymphocytes cultured from each malformed child with abnormal dermatoglyphic patterns. At least 20 cells were counted and analyzed by conventional staining techniques, and 15 karyotypes were prepared (Moorhead et al., 1960). Cases of suspected chromosome aberration were analyzed by chromosome-banding techniques (Seabright, 1971). Cases suspected of mosaicism were investigated by chromosome analysis of other tissues such as bone marrow or skin fibroblasts.

\section{RESULTS}

The series included 11,348 males; 10,715 females; 145 sets of twins; and 3 sets of triplets. No multiple congenital malformations were found in either the twins or the triplets. Four hundred and fifty-five cases had chromosome studies after screening for autosomal aberration. The prevalence of specific (malformation) syndromes is summarized in Table 1 . We found; 3 cases with trisomy-13 (including 1 with mosaicism) syndrome; 4 with trisomy-18 syndrome (including 1 with mosaicism); 24 with Down syndrome (including 1 with mosaicism); 2 with cri-du-chat syndrome; 1 with partial trisomy $5 \mathrm{p} ; 1$ with partial monosomy $10 \mathrm{p} ; 1$ with partial monosomy 4p; 1 with Hallermann-Streiff syndrome; 1 with Treacher-Collins syndrome; 2 with achondroplasia; 2 with arthrogryposis; 2 with hemihypertrophy (of the entire left side of the body); 1 with Wiedemann-Beckwith syndrome; 1 with asplenia syndrome; 1 with Klippel-Trenaunay-Weber syndrome; 1 with Marfan syndrome; 1 with Carpenter syndrome; 1 with Goldenhar syndrome; and 1 with Aberrant tissue syndrome. All the Marfan syndrome and the achondroplasia cases appeared to be sporadic. Besides these 51 cases, we encountered 32 cases with multiple con- 
Table 1. Prevalence of specific malformation syndromes (July 1972-December 1982).

\begin{tabular}{|c|c|c|c|}
\hline Syndromes & Total & $\begin{array}{l}\text { Prevalence } \\
\text { per } 1,000\end{array}$ & $\begin{array}{l}\text { Prevalence reported } \\
\text { in previous surveys a }\end{array}$ \\
\hline $\mathrm{XYY}$ individuals & 6 & 0.86 & 1.1 (male birth) \\
\hline Klinefelter & 2 & 0.29 & 1. 18 (male birth) \\
\hline Turner & 1 & 0.38 & 0.4 (female birth) \\
\hline Triple $X$ & 1 & 0.38 & 0.8 (female birth) \\
\hline Trisomy 13 & 3 & 0.14 & $0.1-0.25$ \\
\hline Trisomy 18 & 4 & 0.18 & 0.13 \\
\hline Trisomy 21 & 24 & 1.09 & 1.00 \\
\hline cri-du-chat & 2 & 0.09 & 0.10 \\
\hline Partial trisomy $5 \mathrm{p}$ & 1 & 0.05 & unavailable \\
\hline Partial monosomy $10_{\mathrm{p}}$ & 1 & 0.05 & unavailable \\
\hline Partial monosomy $4 p$ & 1 & 0.05 & unavailable \\
\hline Hallermann-Streiff & 1 & 0.05 & rare \\
\hline Treacher-Collins & 1 & 0.05 & unavailable \\
\hline Achondroplasia & 2 & 0.09 & 0.10 \\
\hline Arthrogryposis & 2 & 0.09 & rare \\
\hline Hemihypertrophy & 2 & 0.09 & unavailable \\
\hline Wiedemann-Beckwith & 1 & 0.05 & unavailable \\
\hline Asplenia & 1 & 0.05 & unavailable \\
\hline Klippel-Trenaunay-Weber & 1 & 0.05 & unavailable \\
\hline Marfan & 1 & 0.05 & 0.02 \\
\hline Carpenter & 1 & 0.05 & unavailable \\
\hline Goldenhar & 1 & 0.05 & unavailable \\
\hline Aberrant tissue & 1 & 0.05 & rare \\
\hline
\end{tabular}

a Warkany, 1977; de Grouchy and Turleau, 1977.

genital malformations, for whom we were unable to make precise diagnosis. Chromosome studies for all these infants with multiple malformations were done, and all of them showed normal karyotypes.

The sex chromosomal abnormalities so far detected in this survey were 8 in male and 2 in female newborn babies, as shown in Table 1 comparing with the data on Caucasian infants (Warkany, 1971; de Grouchy and Turleau, 1977). As sex chromatin examinations and chromosome analysis were delayed, 8 cases in 6,977 phenotypically male babies and 2 cases in 2,633 phenotypically female babies were detected until now. The karyotype of these cases were as follows; 6 with XYY individuals (including 1 with $46, X Y,-D,+t(D p ; Y q)$ and 1 with $46, X Y / 47, X Y Y)$, 2 with $47, \mathrm{XXY}, 1$ with $45, \mathrm{X}$ and 1 with 47 , XXX.

The birth weight of the affected infants is compared with the intrauterine growth 
of normal Japanese babies (Funakawa, 1968). Most of the affected babies had normal weights for gestational age, with the exception of five, who had autosomal abnormalities, one, who had Turner syndrome, and one, who had arthrogryposis multiplex congenita. These were small-for-date infants. Of particular interest was

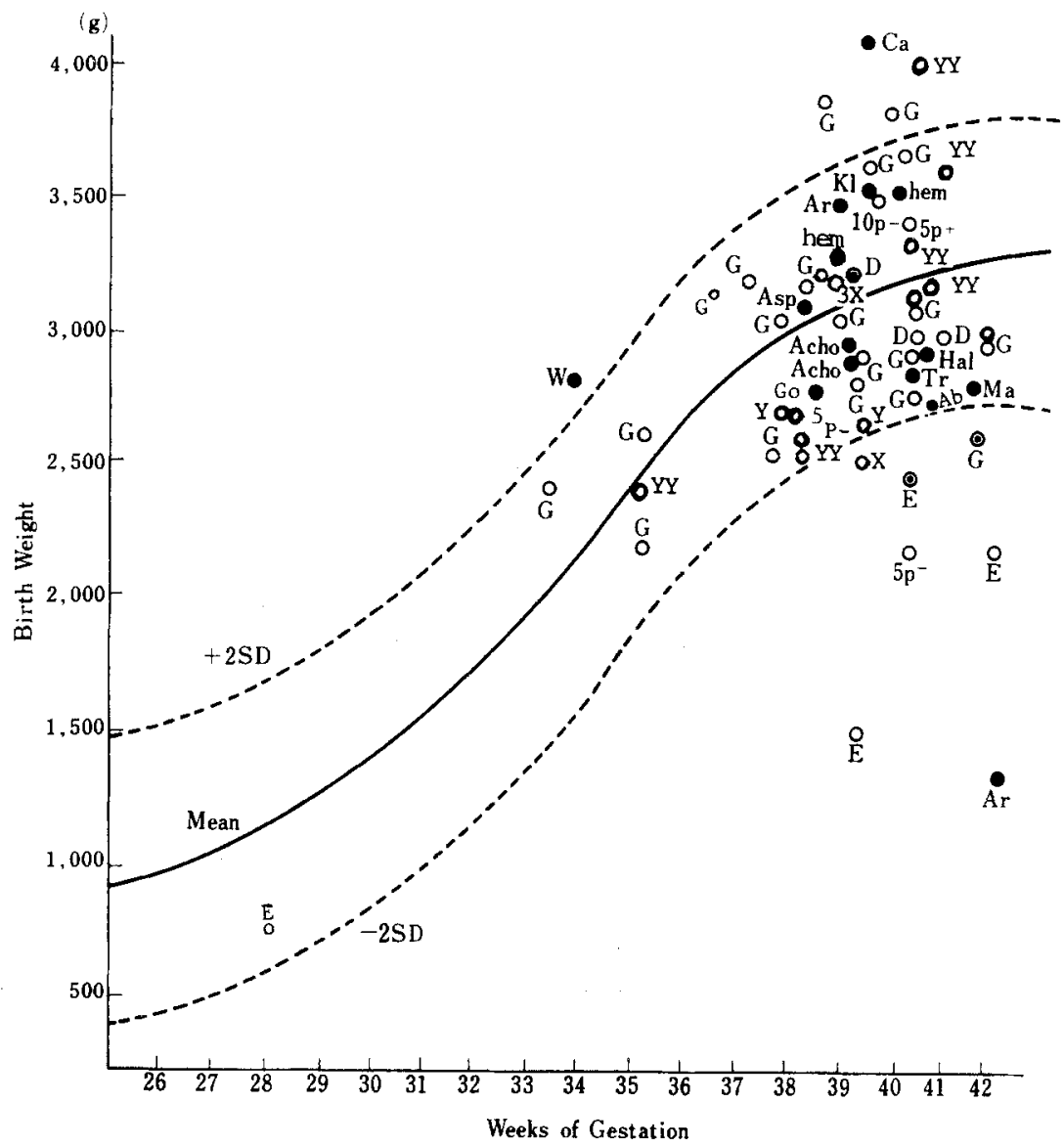

o Chromosamal aberrations Mosaicism

- Other syndromes

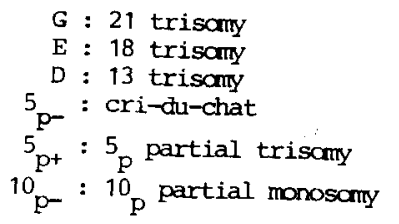

$\begin{aligned} & Y Y: X Y Y \\ & 3 X: X X X \\ & X: X O \\ & Y: X X Y \\ & \text { Ar }: \text { Arthrogryposis } \\ & \text { Acho }: \text { Achondroplasia } \\ & \text { hem }: \text { Hemihypertrophy } \\ & \text { Hal : Hallermann-Streiff }\end{aligned}$

W : Wiedemann-Beckwith

Asp : Asplenia

Kl : Klippel-Trenaunay-Weber

Ma : Marfan

Tr : Treacher-Collins

Go : Goldenhar

$\mathrm{Ca}$ : Carpenter

$\mathrm{Ab}$ : Aberrant tissue

Fig. 2. Birth weight of infants with congenital malformations compared to normal intrauterine growth of Japanese infants. 
Table 2. Maternal age category in 5 years divisions (1972.7-1982.12).

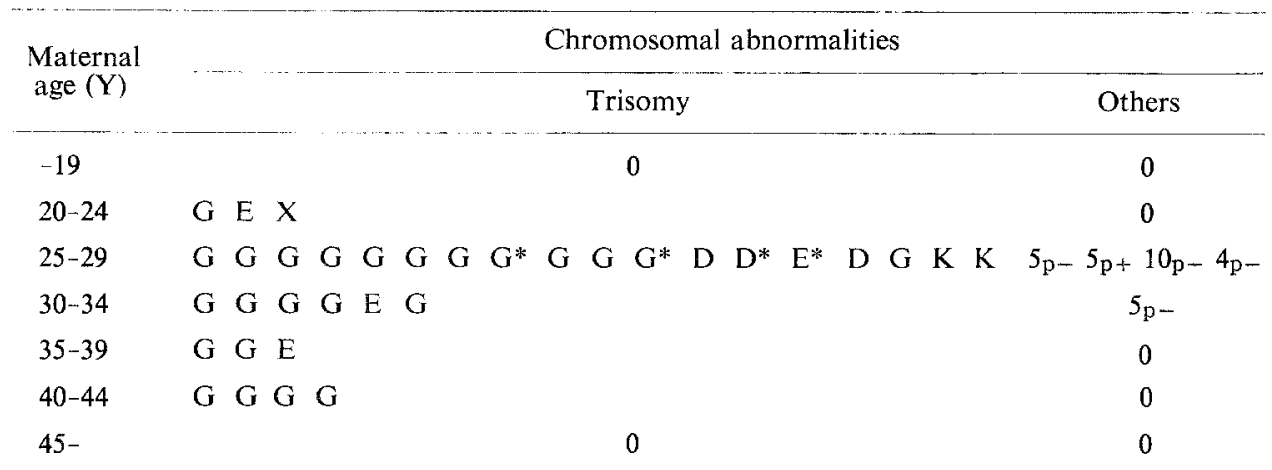

D, 13 trisomy; E, 18 trisomy; G, 21 trisomy; K, Klinefelter; X, triplex X. * Mosaicism.

the observation that three out of four cases with trisomy-18 syndrome were smallfor-date infants (Fig. 2).

The maternal ages for each case with chromosomal abnormalities (except $\mathrm{XO}$ and XYY) are summarized in Table 2. The average maternal age was 31.2 years for the 30 cases (except mosaicism) with trisomy syndromes, 30.9 years for cases of chromosomal abnormalities, and 27.4 years for the affected cases except trisomytype abnormalities. These ages were higher than the average maternal age for normal control babies in this hospital $(27.65 \pm 6.05)$, and these data shown in Table 2 showed that the incidence of trisomy depended on maternal age. The range of maternal ages at delivery was similar to that in the general population in Japan.

\section{DISCUSSION}

The purpose of this study was to establish the incidence of several malformation syndromes and major chromosomal abnormalities among the newborn population in Japan. Ideally, successful karyotypes should be obtained on all newborn infants in this study, but it was not feasible for all newborn infants to be examined by chromosome analysis. Specific tools were selected, therefore, to screen for chromosome aberrations, including sex-chromatin examination as an index of sex chromosome aberrations, and a "triad" (congenital malformations, mental retardation, and abnormal dermatoglyphics) for autosomal aberrations. In addition, low birth weight, failure to thrive, and history of spontaneous abortion in mothers were supplementary tools for screening for autosomal aberrations.

The abnormalities were detected by means of chromosome analysis of lymphocytes cultured from those infants selected on the basis of the two screening methods. It was assumed, with reasonable justification, that these methods would detect all major abnormalities of chromosome number or structure. Such methods will not, however, detect clinically normal infants with balanced chromosome rear- 
rangements or with minute unidentifiable chromosome fragments in most cells, or those who carry distinctive chromosome variants, such as the $\mathrm{Dp}+$ and $\mathrm{Gp}+$.

Our study began in the summer of 1972 and the first report on a survey of 14,430 newborn infants born until the end of 1978 has been described (Higurashi et al., 1980). The present survey, adding the first report, describes the new cases with multiple malformation syndromes after the beginning of 1979 , cases with sex chromosomal abnormalities, which have been detected after the screening for sex chromosomal abnormalities, and the cases with mainly single malformations who were born between the middle of 1972 and the end of 1982. This may be the first large survey of specific malformation syndromes in Japan, even in the world. Although a large cytogenetic survey of an unselected series of Caucasian babies has been reported, no survey on specific malformation syndromes has been reported (Friedrich and Nielsen, 1973; Hamerton et al., 1975; Lubs and Ruddle, 1975).

The birth prevalence of each specific malformation syndrome is a representative of the general population, since the newborn sample was typical for Japan. The neonates were not selected from a specific group and included all socioeconomic classes. In addition, the distribution of maternal age delivery was similar to that of the general Japanese population.

The birth prevalences of the three major autosomal tisomies are very similar with those found in white infants (Table 1). The birth prevalence of other syndromes with autosomal abnormalities is low and, therefore, no conclusions can be drawn regarding their prevalence from the present survey. The birth prevalence of cases with sex chromosomal abnormalities is also lower than that in white babies, because most cases with sex chromosomal abnormalities show no obvious manifestations neonatally and remain undetected, in this survey. With respect to occurrence of other nonautosomal syndromes, prevalence estimates are not very reliable, because of the small sample size on which they are based. It will be important to accumulate data to provide more definitive informations on these abnormalities.

In this survey, the average maternal age for a random sample of 1,000 mothers was $27.65 \pm 6.05$, which is near the Japanese average. In contrast, the average maternal age for mothers of infants with trisomy syndromes (except XYY) was 31.2 years. The age of mothers with trisomic babies, particularly those with Down syndrome, was higher than that of those with normal babies, but the difference was not significant.

Comparison of birth weights of affected cases with normal ranges for gestational age with those of normal Japanese babies indicated that affected babies were not always small-for-dates. Although the birth weight of infants with autosomal abnormalities is often said to be below that of controls of similar gestational age, as noted by Smith and Mckeown (1955), we found the divergence was small, in that the birth weight of 21 out of 24 cases with trisomy 21 was within a mean $\pm 2 S D$. 
Acknowledgements This research was supported by a grant from the Scientific Fund of the Ministry of Health and Welfare, and the Ministry of Education, Science and Culture of Japan, and grant from Research a Fund of Chiyoda Life Insurance Company.

\section{REFERENCES}

de Grouchy, J. and Turleau, C. 1977. Clinical atlas of human chromosomes. John Wiley and Sons, New York.

Friedrich, U. and Nielsen, J. 1973. Chromosomes studies in 5,049 consecutive newborn children. Clin. Genet. 4: 333-343.

Funakawa, H. 1968. Gestational ages and intrauterine growth. Acta Neonatol. Jpn. 4: 129-135. Hamerton, J.L., Canning, N., Ray, M., and Smith, S. 1975. A cytogenetic survey of 14,069 newborn infants. Clin. Genet. 8: 233-243.

Higurashi, M., Segawa, M., Matsui, I., Ihnuma, K., and Nakagome, Y. 1977. Screening for autosomal aberrations. Acta Paediatr. Scand. 66: 501-504.

Higurashi, M., Iijima, K., Sugimoto, Y., Ishikawa, N., Hoshina, H., Watanabe, N., and Yoneyama, K. 1980. The birth prevalence of malformation syndromes in Tokyo infants; A survey of 14,430 newborn infants. Am. J. Med. Genet. 6: 189-194.

Lubs, H.A. and Ruddle, F.H. 1975. Chromosomal abnormalities in the human population. Science 169: 495-497.

Matsui, I., Higurashi, M., and Naganuma, M. 1969. Chromosomal aberrations. Obstet. Gynecol. 36: 131-145 (in Japanese).

Moothead, P.S., Nowell, P.C., Mellman, W.J., Battips, D.M., and Hungerford, D.A. 1960 . Chromosome preparations of leukocytes cultured from human peripheral blood. Exp. Cell. Res. 20: $613-618$.

Seabright, M. 1971. A rapid technique for human chromosome. Lancet 2: 971-972

Smith, A. and Mckeown, T. 1955. Prenatal growth of Mongoloid defectives. Arch. Dis. Child, 30: $257-259$.

Warkany, J. 1971. Congenital malformations. Year book Medical Publishers, Chicago. 